\title{
Relação entre a linfopenia e a persistência da papilomatose alimentar em bovinos intoxicados crônica e espontaneamente por samambaia (Pteridium aquilinum) ${ }^{1}$
}

\author{
Eduardo K. Masuda², Glaucia D. Kommers ${ }^{3 *}$, Fabio B. Rosa ${ }^{4}$, Claudio S.L. Barros ${ }^{3}$, \\ Rafael A. Fighera ${ }^{3}$ e José V.M. Piazer ${ }^{5}$
}

\begin{abstract}
Masuda E.K., Kommers G.D., Rosa F.B., Barros C.S.L., Fighera R.A. \& Piazer J.V.M. 2011. [Relationship between lymphopenia and the persistence of alimentary papillomatosis in cattle chronically and spontaneously poisoned by bracken fern (Pteridium aquilinum).] Relação entre a linfopenia e a persistência da papilomatose alimentar em bovinos intoxicados crônica e espontaneamente por samambaia (Pteridium aquilinum). Pesquisa Veterinária Brasileira 31(5):383-388. Laboratório de Patologia Veterinária, Departamento de Patologia, Centro de Ciências da Saúde, Universidade Federal de Santa Maria, Avenida Roraima 1000, Santa Maria, RS 97105900, Brazil. E-mail:glaukommers@yahoo.com

Bovine papillomavirus type-4 (BPV-4) is responsible for the development of papillomas in the upper digestive tract (UDT) of cattle. The necessary steps for the development, growth and regression of papillomas are intimately related with the immunological status of the animal. The consumption of bracken fern (Pteridium aquilinum) has been pointed out as the major factor involved in the persistence of BPV-4 infection of the UDT. The theory involving the relationship between alimentary papillomas and the formation of squamous cell carcinomas (SCCs) suggests the persistence of alimentary papillomatosis through a chronic immunosupressive lymphopenic state induced by bracken fern. The papillomas would serve then as a development site of SCCs through the interaction of BPV-4 oncoproteins and bracken carcinogens. The objective of this study was to evaluate the relationship between lymphopenia and alimentary papillomatosis in spontaneous cases of chronic bracken fern poisoning of cattle. The age, intensity of papillomatosis and the leukon were evaluated of 40 cattle with SCCs of the UDT. Three animals had leukopenia and one had neutrophilia. The mean lymphocyte count (and standart deviation) of mild, moderate and severe papillomatosis was $5,395( \pm 1,696) / \mathrm{mm}^{3}, 4,560( \pm 1,561) / \mathrm{mm}^{3}$ and $5,007( \pm 1,786) / \mathrm{mm}^{3}$, respectively. There were no statistically significant differences between the intensity of alimentary papillomasis, age and the lymphocyte count. Immunosupression by lymphopenia was a sporadic finding (three cases) in the present study. The results demonstrate that the persistence of alimentary papilomatosis in spontaneous cases of bracken fern-related SCCs of the UDT is not related to lymphopenia and it may be related to other immunological factors.
\end{abstract}

INDEX TERMS: Poisonous plant, Pteridium aquilinum, papillomatosis, bovine papillomavirus type 4, plant poisoning, diseases of cattle.

\footnotetext{
${ }^{1}$ Recebido em 18 de novembro de 2010.

Aceito para publicação em 26 de novembro de 2010.

Parte da tese de doutorado do primeiro autor (bolsista CAPES).

2 Programa de Pós-Graduação em Medicina Veterinária, área de concentração em Patologia Veterinária, Centro de Ciências Rurais, Universidade Federal de Santa Maria (UFSM), Santa Maria, RS 97105900, Brasil.
}

\footnotetext{
${ }^{3}$ Departamento de Patologia, Universidade Federal de Santa Maria, Avenida Roraima 1000, Santa Maria, RS. *Autor para correspondência: glaukommers@yahoo.com

${ }^{4}$ Graduação em Medicina Veterinária, UFSM, Santa Maria, RS. Bolsista $\mathrm{PIBIC/CNPq/UFSM.}$

${ }^{5}$ Inspetoria Veterinária de Jaguari, Rua Carlos Calegaro 290, Jaguari, RS 97760-000, Brasil.
} 
RESUMO.- Papilomavírus bovino tipo 4 (BPV-4) é responsável pelo desenvolvimento de papilomas no trato alimentar superior (TAS) de bovinos. Os passos necessários para o crescimento, o desenvolvimento e a regressão dos papilomas estão intimamente relacionados com o estado imunológico do animal. A ingestão de samambaia (Pteridium aquilinum) tem sido relacionada como o principal fator envolvido na persistência da infecção pelo BPV-4 no TAS. A teoria que estabelece a relação entre papilomatose alimentar e a formação de CCEs sugere a produção de um estado imunossupressivo crônico pela planta, permitindo a persistência dos papilomas no TAS. Os papilomas serviriam então como sítios de desenvolvimento dos CCEs através da interação entre as proteínas do BPV-4 e os carcinógenos da samambaia. O objetivo deste estudo foi avaliar a relação entre a quantidade de linfócitos circulantes e a papilomatose alimentar em casos de intoxicação espontânea crônica por $P$. aquilinum em bovinos com CCE no TAS. Quarenta bovinos com CCEs no TAS foram avaliados quanto à idade, à intensidade da papilomatose alimentar no TAS e ao leucograma. Três bovinos tinham leucopenia e um apresentava neutrofilia. A média de linfócitos foi de 5.395 $( \pm 1.696)$ na papilomatose leve, $4.560( \pm 1.561)$ na moderada e $5.007( \pm 1.786)$ na acentuada. Não houve diferença estatisticamente significativa entre o grau de papilomatose, a idade e a quantidade de linfócitos circulantes. Imunossupressão por linfopenia foi um achado esporádico (três casos) neste estudo. Os resultados indicam que a persistência da papilomatose alimentar em casos espontâneos de intoxicação crônica por samambaia em bovinos não tem relação com a quantidade de linfócitos circulantes e que talvez esteja relacionada a outros fatores imunológicos.

TERMOS DE INDEXAÇÃO: Plantas tóxicas, papilomatose, papilomavírus bovino tipo 4, intoxicação por planta, Pteridium aquilinum, doenças de bovinos.

\section{INTRODUÇÃO}

Papilomavírus bovino tipo 4 (BPV-4) é um vírus DNA pertencente à família Papillomaviridae, responsável pelo desenvolvimento de papilomas no trato alimentar superior (TAS) de bovinos (Campo et al. 1980). Quando a papilomatose alimentar se desenvolve em animais saudáveis, ela é auto-limitante (Nicholls et al. 2001).

Os passos necessários para o crescimento, o desenvolvimento e a regressão dos papilomas estão intimamente relacionados com o estado imunológico do animal (Nicholls \& Stanley 2000, Howley \& Lowy 2006). A infecção viral pelo BPV-4 se estabelece na mucosa do TAS através de pequenas lesões epiteliais (Howley \& Lowy 2006). O vírus induz a proliferação das células basais infectadas e leva à formação de papilomas, com posterior liberação dos viriões através da descamação do estrato córneo (Anderson et al. 1997).

Fatores imunossupressores predispõem animais e humanos a desenvolverem papilomatose (Duncan et al. 1975, Campo \& Jarrett 1986, Borzacchiello et al. 2003). Em humanos, condições imunossupressivas que afetam os linfócitos (por exemplo: gravidez, quimioterapia ou infecção pelo vírus da imunodeficiência humana) aumentam a chance da persistência da infecção pelo papilomavírus (Duncan et al. 1975, Howley \& Lowy 2006, Woodman et al. 2007). Em bovinos, fatores imunossupressivos, como a infecção pelo vírus da diarreia viral bovina (Borzacchiello \& Roperto 2008), corticoterapia (Tsirimonaki et al. 2003) e ingestão de samambaia (Pteridium aquilinum) (Jarrett et al. 1978, Jarrett 1985, Campo \& Jarrett 1986, Campo et al. 1994) tem sido relacionados como os principais fatores envolvidos na persistência da infecção pelo BPV-4.

Bovinos que pastoreiam em áreas altamente infestadas por samambaia frequentemente são acometidos por papilomatose alimentar e por carcinomas de células escamosas (CCEs) no TAS (Döbereiner et al. 1967, Tokarnia et al. 1969, Jarrett et al. 1978, Jarrett 1980, Gava et al. 2002, Souto et al. 2006). A teoria da relação entre papilomatose alimentar por BPV-4, samambaia e a formação de CCEs no TAS foi estabelecida após um estudo experimental de intoxicação crônica por Pteridium aquilinum (Campo et al. 1994). Na teoria da patogênese dos CCEs no TAS, denominada "síndrome papiloma-carcinoma", o ptaquilosídeo presente na samambaia seria o responsável por estabelecer um estado imunossupressivo linfopênico crônico e persistente. Essa diminuição da quantidade de linfócitos circulantes predisporia os animais a desenvolver papilomatose persistente $e$ disseminada. Tais papilomas serviriam então como sítios de desenvolvimento dos CCEs através da interação entre as oncoproteínas do BPV-4 e os carcinógenos da samambaia (Campo et al. 1994, Anderson et al. 1997, Campo 1997).

O principal objetivo deste estudo foi, portanto, avaliar se há relação entre a quantidade de linfócitos circulantes e a papilomatose alimentar em casos de intoxicação espontânea crônica por samambaia em bovinos com CCE no TAS.

\section{MATERIAL E MÉTODOS}

Foram analisados o leucograma e os aspectos clinicopatológicos de 40 bovinos com diagnóstico de intoxicação crônica por samambaia (Pteridium aquilinum) na forma clínica crônica de CCEs no TAS, no período de 2006 a 2010. Os bovinos eram provenientes de áreas altamente infestadas por samambaia e foram avaliados quanto à idade, à intensidade da papilomatose alimentar no TAS e ao leucograma.

A idade dos bovinos foi computada no momento do diagnóstico clínico de CCE no TAS. As idades absolutas foram tabuladas e analisadas quanto à distribuição de frequência.

A papilomatose alimentar foi classificada quanto à intensidade em: leve, moderada ou acentuada. Quanto a sua localização, ela foi classificada regionalmente em: cranial (compreendendo a região da base da língua, faringe/orofaringe e epiglote), média (esôfago), caudal (entrada do rúmen e rúmen). Quando os papilomas estavam presentes em todo o TAS, a papilomatose foi classificada como disseminada.

Foi classificada como papilomatose leve quando os bovinos apresentavam poucos papilomas e que se localizavam regionalmente no TAS, principalmente na região cranial. Moderada quantidade de papilomas que se localizavam regionalmente ou em toda extensão do TAS foi classificada como papilomatose moderada. Papilomatose acentuada ocorreu 
quando grande quantidade de papilomas foi encontrada disseminada em toda extensão do TAS.

O sangue para realização do leucograma foi coletado em tubos de ensaio com EDTA no momento do diagnóstico clínico (dias ou poucas semanas antes da morte) ou momentos antes da morte do animal. A técnica constituiu-se de: contagem de leucócitos em câmara de Neubauer utilizando-se líquidos de Türk como diluente e análise de esfregaços corados por panótico rápido para a diferenciação celular e pesquisa de alterações morfológicas nas células. Foram utilizados valores de referência da espécie bovina segundo Jain (1986).

Os resultados dos leucogramas foram comparados com os graus de papilomatose alimentar e com a idade dos animais através da análise de variância com o método de Holm-Sidak. Em todos os testes, $\mathrm{P}<0.05$ foi considerado estatisticamente significativo.

\section{RESULTADOS}

A idade dos bovinos diagnosticados com CCEs no TAS e que pastoreavam em áreas com samambaia variou de 3 a 12 anos, com média de 8 anos (Fig.1).

O resultado completo do leucograma está apresentado no Quadro 1. No leucograma, leucopenia foi observada em três casos. Linfopenia foi a principal causa da diminuição de leucócitos circulantes e ocorreu nos três casos. Neutropenia também foi observada em um caso. Em seis bovinos, leucocitose por neutrofilia e com desvio à esquerda foi o achado mais importante. Eosinofilia ocorreu em um caso. Não houve alteração significativa no leucograma dos trinta bovinos restantes.

Papilomatose leve (Fig.2A) foi observada em 17 casos. Nesses, poucos papilomas estavam localizados principalmente na região cranial do TAS, compreendendo a face ventrolateral da base da língua e faringe/orofaringe. Nos 15 casos de papilomatose moderada (Fig.2B), os papilomas localizavam-se regionalmente na parte cranial

Fig.2. Graus de papilomatose alimentar em bovinos intoxicados crônica e espontaneamente por Pteridium aquilinum. Região cranial do trato alimentar superior. (A) Papilomatose leve. (B) Papilomatose moderada. (C) Papilomatose acentuada.

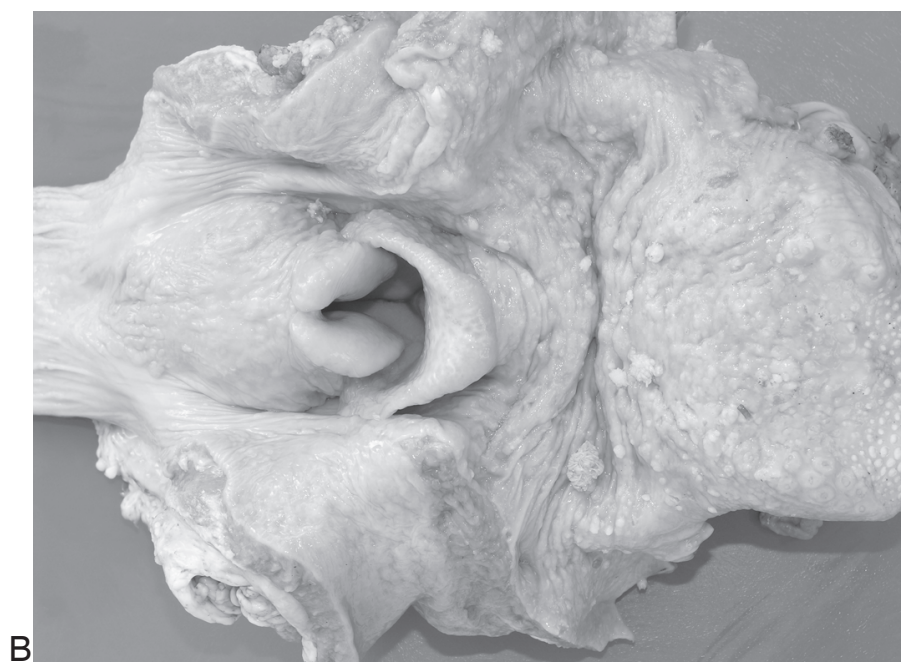

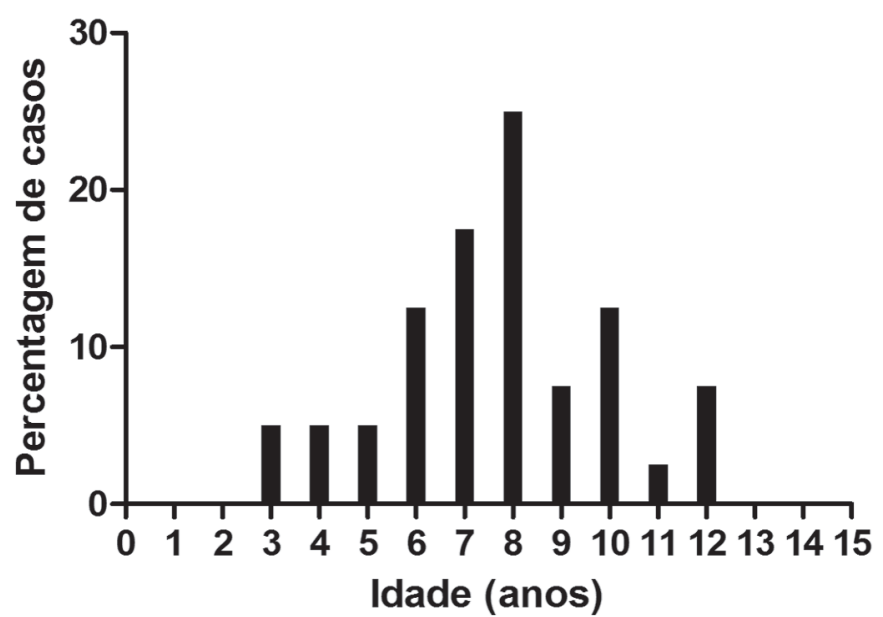

Fig.1. Distribuição de frequência das idades dos 40 bovinos. A média de idade é de 8 anos, variando de 3 a 12 anos.

ou em toda extensão do TAS. Papilomatose acentuada (Fig. 2C) ocorreu em oito casos e se caracterizava por grande quantidade de papilomas, em diversos estágios de desenvolvimento, em toda extensão do TAS.
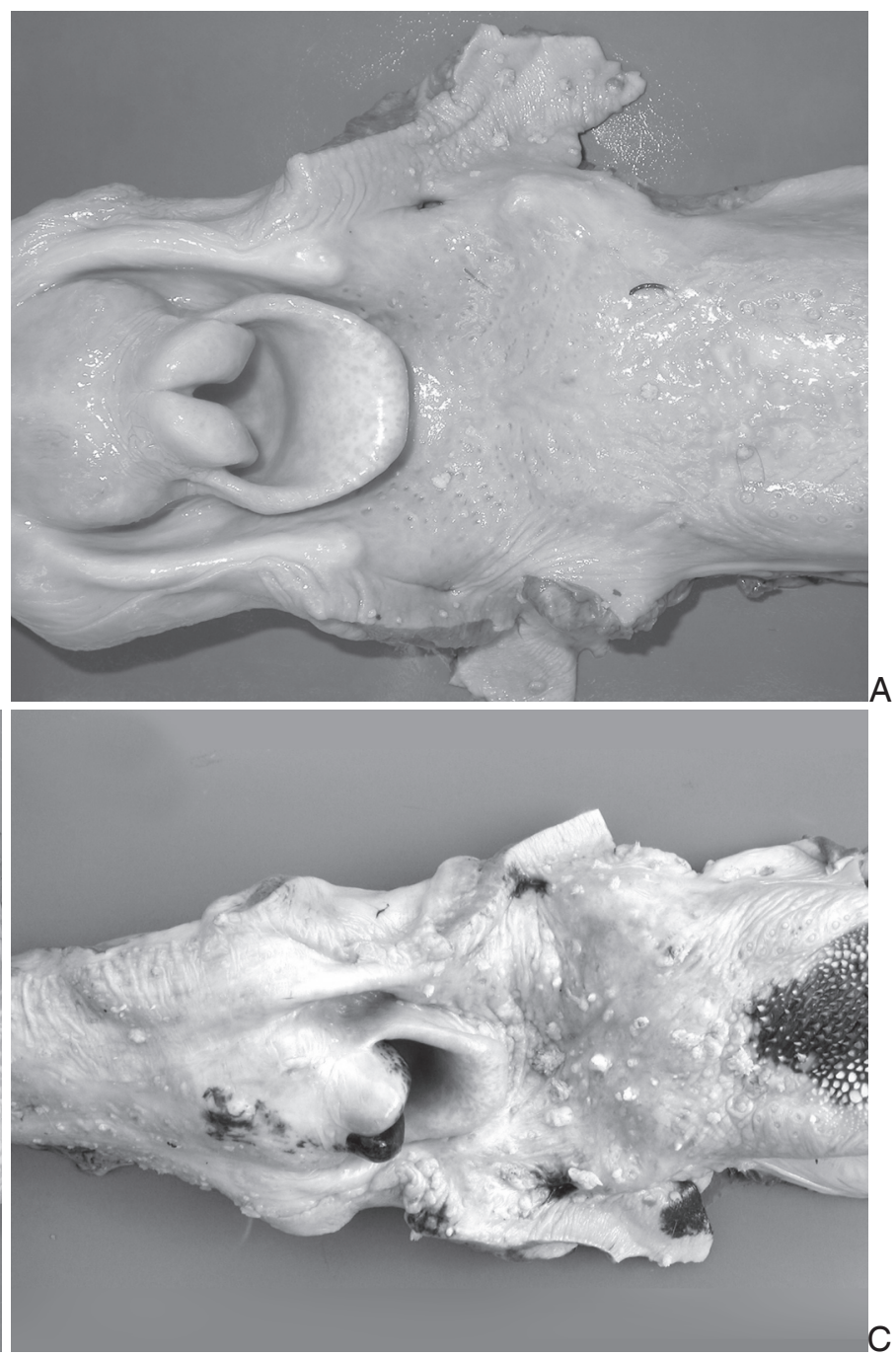
Quadro 1. Idade, leucograma e intensidade da papilomatose alimentar de bovinos intoxicados crônica e espontaneamente por Pteridium aquilinum com a forma clínica de carcinoma de células escamosas no trato alimentar superior

\begin{tabular}{|c|c|c|c|c|c|c|c|c|c|}
\hline Bovino & Idade & $\begin{array}{c}\text { Leucócitos } \\
\left(/ \mathrm{mm}^{3}\right) \\
4.000-12.000\end{array}$ & $\begin{array}{l}\text { Neutrófilos } \\
\left(/ \mathrm{mm}^{3}\right) \\
600-4.000\end{array}$ & $\begin{array}{c}\text { Bastonetes } \\
\left(/ \mathrm{mm}^{3}\right) \\
0-120\end{array}$ & $\begin{array}{c}\text { Linfócitos } \\
\left(/ \mathrm{mm}^{3}\right)^{1} \\
2.500-7.500\end{array}$ & $\begin{array}{c}\text { Monócitos } \\
\left(/ \mathrm{mm}^{3}\right) \\
25-840\end{array}$ & $\begin{array}{c}\text { Eosinófilos } \\
\left(/ \mathrm{mm}^{3}\right) \\
0-2.400\end{array}$ & $\begin{array}{c}\text { Basófilos } \\
\left(/ \mathrm{mm}^{3}\right) \\
0-200\end{array}$ & $\begin{array}{l}\text { Papilomatose } \\
\quad(L, M, A)\end{array}$ \\
\hline 1 & 5 & 22.100 & 12.818 & 2.873 & 5.525 & 442 & 0 & 0 & $\mathrm{M}$ \\
\hline 3 & 8 & 5.400 & 1.728 & 0 & 2.970 & 108 & 594 & 0 & A \\
\hline 4 & 8 & 8.100 & 2.106 & 81 & 5.589 & 162 & 162 & 0 & A \\
\hline 5 & 7 & 6.000 & 1.680 & 120 & 3.480 & 540 & 180 & 0 & $\mathrm{M}$ \\
\hline 6 & 8 & 5.100 & 1.734 & 102 & 3.009 & 153 & 102 & 0 & A \\
\hline 9 & 6 & 8.700 & 2.001 & 0 & 5.655 & 0 & 1.044 & 0 & A \\
\hline 10 & 8 & 8.300 & 2.739 & 0 & 5.395 & 83 & 83 & 0 & $\mathrm{~L}$ \\
\hline 11 & 10 & 4.500 & 1.260 & 0 & 2.880 & 45 & 315 & 0 & $\bar{M}$ \\
\hline 12 & 8 & 5.200 & 1.768 & 52 & 3.120 & 156 & 104 & 0 & A \\
\hline 13 & 3 & 7.000 & 2.100 & 0 & 4.200 & 70 & 630 & 0 & $M$ \\
\hline 14 & 3 & 11.000 & 3.300 & 110 & 7.260 & 110 & 220 & 0 & $\mathrm{~L}$ \\
\hline 15 & 5 & 12.000 & 3.120 & 120 & 7.200 & 120 & 1.440 & 0 & A \\
\hline 20 & 7 & 4.300 & 1.591 & 0 & 2.537 & 129 & 43 & 0 & $\mathrm{~L}$ \\
\hline 21 & 4 & 6.800 & 2.380 & 68 & 4.216 & 68 & 68 & 0 & $\mathrm{M}$ \\
\hline 22 & 10 & 16.200 & 5.832 & 324 & 6.804 & 162 & 2.916 & 162 & $\mathrm{~L}$ \\
\hline 23 & 6 & 8.100 & 3.240 & 0 & 4.212 & 243 & 405 & 0 & $M$ \\
\hline 24 & 8 & 9.600 & 2.880 & 0 & 6.432 & 192 & 96 & 0 & $\mathrm{~L}$ \\
\hline 25 & 6 & 7.600 & 2.584 & 0 & 4.560 & 152 & 304 & 0 & $\mathrm{M}$ \\
\hline 26 & 12 & 8.900 & 2.225 & 0 & 6.480 & 89 & 178 & 0 & $\mathrm{~L}$ \\
\hline 27 & 12 & 9.100 & 3.276 & 0 & 5.187 & 273 & 364 & 0 & $\mathrm{M}$ \\
\hline 28 & 8 & 14.200 & 8.236 & 284 & 4.686 & 284 & 710 & 0 & $M$ \\
\hline 29 & 12 & 28.400 & 16.756 & 1.420 & 7.100 & 1.704 & 1.420 & 0 & $\mathrm{~L}$ \\
\hline 30 & 9 & 8.200 & 2.870 & 82 & 4.674 & 164 & 410 & 0 & $\mathrm{~L}$ \\
\hline 31 & 6 & 19.800 & 9.900 & 990 & 8.316 & 198 & 198 & 0 & $\mathrm{M}$ \\
\hline 32 & 7 & 8.500 & 2.720 & 85 & 5.355 & 170 & 170 & 0 & L \\
\hline 33 & 7 & 10.600 & 3.286 & 106 & 6.890 & 212 & 106 & 0 & $M$ \\
\hline
\end{tabular}

* Intensidade da papilomatose: (L) leve, (M) moderada e (A) acentuada.

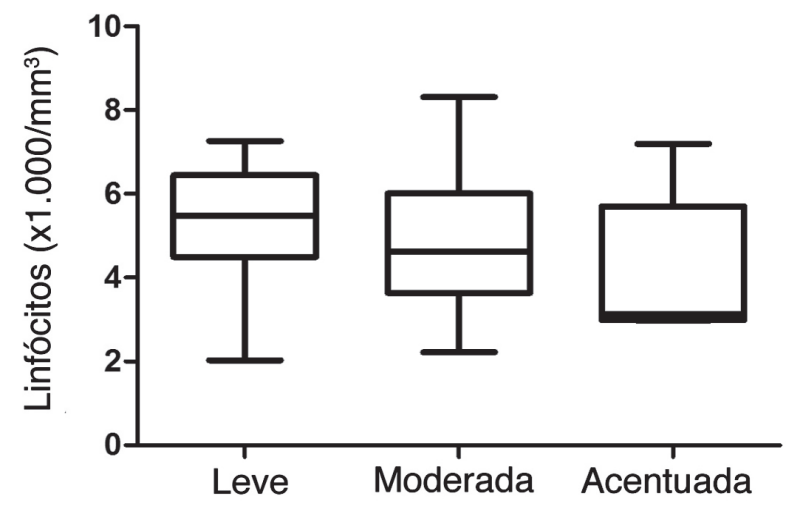

Papilomatose

Fig.3. Relação entre a quantidade de linfócitos e o grau de papilomatose alimentar através da análise de variância e do teste de comparação dos pares (método de Holm-Sidak), estabelecendo intervalo de confiança de $95 \%$.
Não houve diferença estatisticamente significativa entre o grau de papilomatose e a idade dos bovinos ao diagnóstico de CCE. Nos três casos de linfopenia, dois tinham papilomatose leve e um moderada. A média de linfócitos foi de $5.395( \pm 1.696) / \mathrm{mm}^{3}$ na papilomatose leve, 4.560 $( \pm 1.561) / \mathrm{mm}^{3}$ na moderada e $5.007( \pm 1.786) / \mathrm{mm}^{3}$ na acentuada. Não houve diferença estatisticamente significativa entre o grau de papilomatose e a quantidade de linfócitos circulantes (Fig. 3).

\section{DISCUSSÃO}

Bovinos sadios naturalmente ou experimentalmente infectados por BPV-4 recuperam-se de papilomatose alimentar em aproximadamente um ano, através de uma resposta imunológica mediada por células (Campo et al. 1994, Knowles et al. 1996). No entanto, exposição crônica a imunossupressores leva à persistência e à disseminação de papilomas em todo o TAS (Borzacchiello \& Roperto 2008). 
O sistema imune tem, portanto, um papel importante na modulação da severidade da doença associada ao papilomavírus (Nicholls \& Stanley 2000).

A persistência dos papilomas no TAS de bovinos que pastoreiam por longos períodos em áreas com samambaia tem sido relacionada com a ingestão contínua dos princípios químicos presentes na planta. A exposição crônica a esses princípios tóxicos, principalmemente o ptaquilosídeo, levaria os bovinos a desenvolverem imunossupressão por linfopenia crônica, permitindo a persistência e a manutenção dos papilomas no TAS (Campo et al. 1994). Tais papilomas serviriam então como um alvo expandido, devido à constante replicação celular induzida pelo BPV-4, para os carcinógenos da samambaia (Pteridium aquilinum) agirem sinergicamente com o vírus no desenvolvimento dos CCEs (Campo et al. 1994).

Inversamente ao que foi encontrado nos casos experimentais (Campo et al. 1992, Campo et al. 1994), a grande maioria dos casos espontâneos de intoxicação crônica por samamabaia do presente estudo não apresentaram linfopenia no momento do diagnóstico clínico. A quantidade de linfócitos também não foi relacionada com a presença e severidade da papilomatose, nem com a idade dos bovinos. Dessa forma, a linfopenia parece não estar relacionada com a persistência dos papilomas no TAS nos casos espontâneos estudados. Porém, não se pode afirmar que mecanismos imunossupressivos (da planta ou outros fatores) não foram necessários para a infecção inicial pelo BPV-4 e para a disseminação da doença no TAS em época anterior ao momento estudado.

Em bovinos naturalmente infectados por BPV-4, a regressão dos papilomas ocorre através de uma reação mediada por células (Knowles et al. 1996, Anderson et al. 1997). Papilomas em regressão são infiltrados por linfócitos $T$, principalmente T CD4+ e CD8+ (Knowles et al. 1996). Esses linfócitos não proliferam nos locais de regressão dos papilomas (Nicholls \& Stanley 2000) e, portanto, são originários de órgão linfoides. O efeito radiomimético do ptaquilosídeo, que levaria ao achado hematológico de linfopenia crônica presente nos casos experimentais (Campo et al. 1994), poderia explicar a ausência dos linfócitos nos papilomas para a sua regressão. No entanto, a persistência dos papilomas nos animais crônica e espontanemente intoxicados por samambaia deste estudo parece não ter nenhuma relação com a diminuição da quantidade de linfócitos circulantes.

Outros mecanismos podem ser sugeridos na tentativa de explicar o papel do sistema imune na regressão dos papilomas após a infecção. A falha no reconhecimento dos papilomas pelo sistema imune sugere que ele talvez não seja avisado (ou seja desabilitado) pela infecção do BPV4 (Araibi et al. 2006). A habilidade do papilomavírus em persistir tem sido atribuído à natureza do ciclo viral (somente epitelial), fatores do hospedeiro, ao estado de latência viral e/ou à habilidade do papilomavírus em subverter ou evadir o sistema imune (Tindle 2002). É provável que esses fatores contribuam para a demora ao reconhecimento da infecção.
Muitos vírus são capazes de evadir do sistema imune do hospedeiro através da interferência nas vias de apresentação e processamento de antígenos (Piquet 2005). No caso dos papilomavírus, foi demonstrado que em papilomas de casos naturais a oncoproteína viral E5 sobre-regula a expressão de MHC-1, permitindo ao vírus evadir da vigilância imunológica e persistir no epitélio infectado (Ashrafi et al. 2002, Marchetti et al. 2002, Araibi et al. 2006). Este mecanismo de evasão das células do sistema imune, especialmente dos linfócitos T e células nulas (natural-killer cells; NK) (Ashrafi et al. 2002), está presente na infecção natural pelo papilomavírus. No entanto, somente este mecanismo de evasão natural não consegue explicar completamente a persistência dos papilomas em bovinos cronicamente intoxicados por samambaia.

Recentemente, um estudo com extrato de samambaia em camundongos C57BL/6 demonstrou a ação modulatória direta do princípio tóxico sobre células do sistema imune com efeito citotóxico seletivo e direto nas células NK. Camundongos tratados com samambaia tiveram uma diminuição na citotoxicidade mediada pelas células NK, as quais interrompiam suas ações sobre os linfócitos T. A redução seletiva da atividade das células NK (citotoxicidade e produção de interferon gama) poderia estar diretamente envolvida na manutenção dos papilomas e formação de tumores em animais cronicamente intoxicados por samambaia (Latorre et al. 2009). Dessa forma, os efeitos imunotóxicos da samambaia poderiam afetar não apenas a resposta imune contra a infecção viral, mas também a vigilância imunológica para a formação de tumores.

\section{CONCLUSÕES}

Imunossupressão por linfopenia foi um achado esporádico nos casos de intoxicação crônica e espontânea por samambaia em bovinos com a forma clínica de CCEs no TAS deste estudo. Estes resultados indicam que a persistência da papilomatose alimentar em casos naturais não tem relação com a quantidade de linfócitos circulantes e que talvez esteja relacionada a outros fatores imunológicos. Dentre eles, destaca-se a ação das proteínas do papilomavírus e também a ação seletiva do ptaquilosídeo sobre determinadas células do sistema imune, fatores importantes para a regressão dos papilomas. A atuação conjunta desses fatores poderia ser responsável pela manutenção dos papilomas no TAS de bovinos crônica e espontaneamente intoxicados por samambaia.

Agradecimentos.- Ao Conselho Nacional de Desenvolvimento Científico e Tecnológico (CNPq) pelo suporte financeiro (Proc.478692/ 2007-2). G.D. Kommers é Bolsista de Produtividade em Pesquisa do CNPq - Nível 2.

\section{REFERÊNCIAS}

Anderson R.A., Scobie L., O'neil B.W., Grindlay G.J. \& Campo M.S. 1997. Viral proteins of bovine papillomavirus type 4 during the development of alimentary canal tumours. Vet. Journal 154(1):69-78.

Araibi E.H., Marchetti B., Dornan E.S., Ashrafi G.H., Dobromylskyj M., Ellis S.A. \& Campo M.S. 2006. The E5 oncoprotein of BPV-4 does not 
interfere with the biosynthetic pathway of non-classical MHC class I. Virology 353(1):174-183.

Ashrafi G.H., Tsirimonaki E., Marchetti B., O'brien P.M., Sibbet G.J., Andrew L. \& Campo M.S. 2002. Down-regulation of MHC class I by bovine papillomavirus E5 oncoproteins. Oncogene 21(2):248-259.

Borzacchiello G., Ambrosio V., Roperto S., Poggiali F., Tsirimonakis E., Venuti A., Campo M.S. \& Roperto F. 2003. Bovine papillomavirus type 4 in oesophageal papillomas of cattle from the south of Italy. J. Comp. Pathol. 128(2/3):203-206.

Borzacchiello G. \& Roperto F. 2008. Bovine papillomaviruses, papillomas and cancer in cattle. Vet. Res. 39(5):45-74.

Campo M., Moar M.H., Jarrett W.F. \& Laird H.M. 1980. A new papillomavirus associated with alimentary cancer in cattle. Nature 286(5769): 180-182.

Campo M.S. 1997. Bovine papillomavirus and cancer. Vet. Journal 154(3):175-188.

Campo M.S. \& Jarrett W.F. 1986. Papillomavirus infection in cattle: Viral and chemical cofactors in naturally occurring and experimentally induced tumours. Ciba Found. Symp. 120:117-135.

Campo M.S., Jarrett W.F., Barron R., O'neil B.W. \& Smith K.T. 1992. Association of bovine papillomavirus type 2 and bracken fern with bladder cancer in cattle. Cancer Res. 52(24):6898-6904.

Campo M.S., O'neil B.W., Barron R.J. \& Jarrett W.F. 1994. Experimental reproduction of the papilloma-carcinoma complex of the alimentary canal in cattle. Carcinogenesis 15(8):1597-1601.

Döbereiner J., Tokarnia C.H. \& Canella C.F.C. 1967. Ocorrência de hematúria enzoótica e de carcinomas epidermóides no trato digestivo superior em bovinos no Brasil. Pesq. Agropec. Bras. 2:489504.

Duncan J.R., Corbeil L.B., Davies D.H., Schultz R.D. \& Whitlock R.H. 1975. Persistent papillomatosis associated with immunodeficiency. Cornell Vet. 65(2):205-211.

Gava A., Da Silva Neves D., Gava D., De Moura S.T., Schild A.L. \& Riet-Correa F. 2002. Bracken fern (Pteridium aquilinum) poisoning in cattle in southern Brazil. Vet. Hum. Toxicol. 44(6):362-365.

Howley P.M. \& Lowy D.R. 2006. Papillomaviruses, p.2299-2354. In: Knipe D.M., Howley P.M., Griffin D.E., Lamb R.A. \& Martin M.A. (Eds), Fields Virology. $5^{\text {th }}$ ed. Lippincott Williams and Wilkins, Boston, Massachusetts.

Jain N.C. 1986. Schalm's Veterinary hematology. $4^{\text {th }}$ ed. Lea and Febiger, Philadelphia, 1221p.
Jarrett W.F. 1980. Bracken fern and papilloma virus in bovine alimentary cancer. Brit. Med. Bull. 36(1):79-81.

Jarrett W.F. 1985. The natural history of bovine papillomavirus infection. Adv. Viral Oncol. 5:83-101.

Jarrett W.F.H., McNeil P.E., Grimshaw W.T.R., Selman I.E. \& McIntyre W.I.M. 1978. High incidence area of cattle cancer with a possible interaction between an environmental carcinogen and a papillomavirus. Nature 274(5668):215-217.

Knowles G., O'neil B.W. \& Campo M.S. 1996. Phenotypical characterization of lymphocytes infiltrating regressing papillomas. J. Virol. 70(12):8451-8458.

Latorre A.O., Furlan M.S., Sakai M., Fukumasu H., Hueza I.M., Haraguchi M. \& Gorniak S.L. 2009. Immunomodulatory effects of Pteridium aquilinum on natural killer cell activity and select aspects of the cellular immune response of mice. J. Immunotoxicol. 6(2):104-114.

Marchetti B., Ashrafi G.H., Tsirimonaki E., O'brien P.M. \& Campo M.S. 2002. The bovine papillomavirus oncoprotein E5 retains MHC class I molecules in the Golgi apparatus and prevents their transport to the cell surface. Oncogene 21(51):7808-7816.

Nicholls P.K., Moore P.F., Anderson D.M., Moore R.A., Parry N.R., Gough G.W. \& Stanley M.A. 2001. Regression of canine oral papillomas is associated with infiltration of CD4+ and CD8+ lymphocytes. Virology 283(1):31-39.

Nicholls P.K. \& Stanley M.A. 2000. The immunology of animal papillomaviruses. Vet. Immunol. Immunopathol. 73(2):101-127.

Souto M.A.M., Kommers G.D., Barros C.S.L., Piazer J.V.M., Rech R.R., Riet-Correa F. \& Schild A.L. 2006. Neoplasias do trato alimentar superior de bovinos associadas ao consumo espontâneo de samambaia (Pteridium aquilinum). Pesq. Vet. Bras. 26(112-122.

Tindle R.W. 2002. Immune evasion in human papillomavirus-associated cervical cancer. Natl Rev. Cancer 2(1):59-65.

Tokarnia C.H., Döbereiner J. \& Canella C.F.C. 1969. Ocorrência de hematúria enzoótica e carcinomas epidermóides no trato digestivo superior em bovinos no Brasil. II. Estudos complementares. Pesq. Agropec. Bras. 4:209-224.

Tsirimonaki E., O'neil B.W., Williams R. \& Campo M.S. 2003. Extensive papillomatosis of the bovine upper gastrointestinal tract. J. Comp. Pathol. 129(2/3):93-99.

Woodman C.B., Collins S.I. \& Young L.S. 2007. The natural history of cervical HPV infection: unresolved issues. Natl Rev. Cancer 7(1):1122. 